\title{
Os simbolistas: virando o século
}

Vera Lins I UFRJ

Resumo: $O$ artigo examina os escritores simbolistas da virada do século XIX, concentrando-se nos ensaios de dois críticos: o critico de arte e ficcionista, Gonzaga Duque e o crítico de literatura e também ficcionista, Nestor Victor. Em ambos pode-se observar uma reflexão sobre a arte e a cultura brasileira original e já moderna.

Palavras-chave: Simbolismo, ensaio, crítica.

O século XIX, segundo Álvaro Moreyra em suas memórias, ${ }^{1}$ só terminou em 1913, às vésperas da Primeira Guerra Mundial. Esse período de 1880 às primeiras décadas do século XX foi estigmatizado pelas vanguardas modernistas, que dataram o início de tudo em 1922. Mas revisões vêm sendo feitas, e escritores como Euclides da Cunha, Lima Barreto e João do Rio, por exemplo, têm sido republicados, estudados e encenados como no caso de Os sertôes, deixando ver uma discussão de questões cruciais da cultura brasileira neste período, que já não se pode mais chamar de pré-moderno, pois já apresenta impasses e contradições do moderno. ${ }^{2}$

1. MOREYRA, 1954.

2. José Paulo Paes, numa tentativa de rediscutir autores e o momento, propõe ver neste período a presença do art-nouveau, diferenciando-o do Simbolismo por um vitalismo nietzchiano e a "écriture artiste". Ver PAES, 1985. 
Primeira revisão interessante foi feita, em 1964, pelos irmãos Campos, recuperando, para o cânone da invenção, os simbolistas Sousândrade, Kilkerry e ainda Maranhão Sobrinho. O Panorama do movimento simbolista brasileiro, de Andrade Muricy, de 1952, com três reedições, tem um papel importante nessa reavaliação. Franklin de Oliveira, em 1971, fala, em artigo, da importância dos simbolistas como um grupo, reinterpretando a acusação de que se encastelavam em torres de marfim, apontando aí um dissenso com as correntes de pensamento dominantes e o estado de coisas vigente:

Tendo surgido como oposição ao mecanicismo, o simbolismo não poderia deixar de ser contestação do pragmatismo e protesto contra o utilitarismo dominantes na época de seu aparecimento. [...] Os simbolistas negaramse a conferir à arte sentido de utilidade, caráter de bem de consumo. O simbolismo foi uma revolta no interior da própria burguesia. Como tal sofreu fatais limitações: as decorrentes da própria natureza das revoltas abstratas. Na sua luta contra a reificação e a coisificação do homem, não tiveram os simbolistas outro caminho a seguir, a não ser o ingresso nos reinos da ruptura com a sociedade via solidão, pois a sua rebelião se circunscrevia à esfera da pura subjetividade - protesto pelo retraimento, imposto por um mundo gelado, uma ordem social álgida. O "frio sepulcral do desamparo", do verso de Cruz e Souza, foi o seu "sentimento do mundo". Portanto discutível é a eficácia do protesto, e não a existência do protesto. ${ }^{3}$

Notam-se, na consideração do crítico, ecos do ensaio de Adorno, "Palestra sobre lírica e sociedade", em que mostra, na recusa quanto ao mundo e no isolamento do simbolista Stefan George, a relação de sua poesia com o social. Este texto do teórico alemão acaba com a oposição escolar entre arte engajada e arte pela arte.

Contudo, os simbolistas brasileiros foram também ardorosos republicanos e abolicionistas, que depois se desencantaram com o rumo tomado por esses movimentos. A república recém-proclamada, autoritária e positivista, significava o sonho da geração de 70, que lutara por reformas liberais - a abolição, a república e a democracia -, dentro de um pensamento evolucionista. O

3. OLIVEIRA, 1978, p. 238 
pensamento e o comportamento divergentes dos simbolistas, taxados de boêmios beberrões por Machado, impede que sejam aceitos em sua academia e os marginaliza. ${ }^{4}$

Franklin de Oliveira reafirma o que alguns já disseram também: se o parnasianismo não tivesse durado tanto tempo, o nosso modernismo seria outro. Carpeaux, em artigo de 59, "Estrada larga", afirma que, se Cruz e Souza e Alphonsus tivessem, no Brasil, conquistado o prestígio e exercido a influência do simbolista português Eugênio de Castro, "não se teria experimentado entre nós a longa noite do parnasianismo". Na historiografia da literatura brasileira confunde-se simbolismo com parnasianismo, levando em conta apenas a coexistência temporal, o que implica uma desconsideração dos leitores de Mallarmé. A crítica, que, a partir de José Veríssimo, afirmava ressoar nos versos de Cruz e Souza o ritmo do tambor africano, não podia ver o que um crítico posterior, como João Alexandre Barbosa, nos anos 80, reconhece na virada simbolista:

O simbolismo, problematizando a representação por força de uma linguagem que buscava a transcendência do objeto e a anulação do sujeito com a criação de um espaço de aglutinações sonoras e espaciais (de que a obra de Mallarmé é a realização mais completa nos limites de sua impossibilidade), retirava a poesia das amarras naturalistas e exigia a consideração daquilo que se impunha como construção de uma linguagem em que as palavras, ganhando peso e medida, opunham-se à transparência da referencialidade.

O simbolismo é uma corrente melancólica, "spleenética", baudelairiana, que aponta a perda que a modernidade provoca. E melancolia é resistência, como afirma Seebald, ${ }^{7}$ estudando a literatura austríaca. Vanguarda secessionista, aqui os simbolistas talvez sejam mais dissidentes que revolucionários. Mas na autonomia da arte que defendiam estava sua política, ligada à separação radical do mundo da mercadoria.

Segundo Nestor Victor, em 1890 se define, no Rio de Janeiro, com a chegada de Cruz e Souza, o movimento simbolista que começara no sul com a

4. Ver LINS, 1991.

5. CARPEAuX, 1999, p. 812.

6. BARBOSA, 1987 , p. 15 .

7. SEBALD, 2005.

8. VICTOR, 1979, p. 238. 
leitura de Baudelaire, e dos belgas, como Rodenbach. ${ }^{9}$ Aproximava europeus e brasileiros uma sensibilidade insatisfeita com os limites do racionalismo. Buscavam o lado escuro, subterrâneo da razão e uma interioridade que possibilitasse criar outros universos pela imaginação, pelo sonho, pela ficção. ${ }^{10}$ Os versos de Cruz e Souza falam disso de uma forma trágica; seu emparedamento lembra a pedra no caminho de Drummond, que fala de um país bloqueado.

$\mathrm{Na}$ avaliação depreciativa do simbolismo tiveram peso os críticos severos da virada do século que, como mostra João Alexandre Barbosa ${ }^{11}$ em José Veríssimo, não tinham ferramentas teóricas para entender o que se passava. Outros críticos, que davam força ao movimento simbolista, quase não foram ouvidos, como Nestor Victor, que editou Cruz e Souza, e Gonzaga Duque, crítico de artes plásticas e ficcionista, que participou do grupo que se aglutinou à volta da Folha Popular, no Rio, em 1889. Nestor Victor afirma em artigo que "Os simbolistas vieram exatamente assim. Representam eles uma reação contra todos os erros da literatura realista, estreita aliada do cientificismo, inferiormente intelectualista, antimetafísica, prosaica por natureza”.

Escritor muito lido nessa virada de século, Oscar Wilde tem um ensaio, "O crítico como artista", 13 de 1890, com o qual dialogou Lukács, no seu "A alma e as formas", teorizando sobre o ensaio. A visão de crítica de Wilde retoma o primeiro romantismo alemão de Schlegel, Schiller e Schelling, que a via como um desenvolvimento necessário à obra. O escritor inglês diz que a crítica de que fala não se limita a descobrir a real intenção do artista e aceitá-la como um ponto final, mas trata a obra simplesmente como um ponto de onde partir para uma nova criação. Wilde inverte a questão colocada por um dos personagens do diálogo, dizendo que é sua dimensão crítica o que dá valor à obra, pois é a faculdade crítica que inventa novas formas. Não é a crítica que tem de ser criativa; a criação deve ter uma dimensão crítica, questionadora. Sem a faculdade crítica não há criação artística que valha a pena. Para ele, o artista é aquele que coloca problemas. A arte moderna vai ser essa arte crítica, exercida com a autonomia que lhe permite a independência da imaginação (o livre jogo de Schiller). ${ }^{14}$

9. A leitura de Brugges, la morte projetava céus cinzentos na cidade tropical.

10. Ver LINS, 1998.

11. BARBOSA, 1974.

12. VICTOR, 1911, p. 239

13. WILDE, 2003.

14. Ver a discussão de Rancière em Malaise dans l'esthétique (2004). 
À luz das reflexões de Wilde e sua retomada por Lukács, depois discutido por Adorno em "O ensaio como forma", gostaria de ver esses dois críticos simbolistas da virada do século como ensaístas singulares. Lukács retira o ensaio, a crítica, do domínio da ciência e o aproxima da arte, pelo reordenamento inteligível da vida que consegue. O ensaio não é mero registro ou classificação, mas interpretação. Embora fale do já formado e não crie a partir do nada como faz a arte, o ensaio seria um tipo de arte, gênero do intervalo, entre a filosofia e a ficção. O ensaio não se confunde com o ficcional, mas está próximo dele, fazendo do próprio autor o palco da experiência intelectual. ${ }^{15} \mathrm{O}$ italiano Alfonso Berardinelli ${ }^{16}$ diz que a escrita do ensaio sofre de uma instabilidade perpétua. Nele os conceitos ressoam como vozes e entram em cena como máscaras. O ensaio passa do conceito à imagem e da imagem ao conceito, não habita a forma como não habita o sistema, atravessa um e outro. Se insinua nos outros gêneros e sofre sua influência. $O$ ensaísta seria um visionário do pensamento e um dialético da metáfora. Seus fundadores modernos seriam Montaigne e Kierkegaard.

Nestor Victor e Gonzaga Duque, diferentemente dos dogmáticos críticos positivistas, não visam uma construção fechada nos seus textos; levam em conta sua experiência, calcada na história, e têm consciência da linguagem, valorizando a exposição do pensamento. Não temem ser heréticos, como, diz Adorno, ser tradição do ensaio.

Por volta de 1900, o Rio de Janeiro era uma cidade de cafés e confeitarias, em que os boêmios e intelectuais discutiam e, inclusive, escreviam. Nessa virada do século, o movimento boêmio ajudava na relação entre críticos e artistas. Gonzaga Duque conta em seu diário a performance do poeta B. Lopes numa confeitaria do Largo de São Francisco. O poeta era apaixonado por uma senhora, a quem chamavam de Mameluca, e a seguia com "obstinação de fauno". Nesse episódio, o comportamento do poeta boêmio fala da possibilidade de uma outra vida, fora dos parâmetros de contenção burgueses.

Nesse dia veranico, Lopes trazia o diabo nas veias. A vasta sala da confeitaria estava cheia de consumidores. O namoro fervia. No balcão das bebidas apinhava-se uma multidão consumindo chopes e Porto gelado.

15. Ver COSTA LIMA, 1993.

16. BERARDINELLI, 2002 
Entra o poeta, espalhafatoso no seu vestuário, uma camisa azul, enorme laçaria de seda creme, presa sob as pontas largas dum colarinho branco, calças de xadrez, dançando nas pernas, polainas de brim, um pára-sol de foulard amarelo, um chapéu de palha branco, e, na lapela do jaquetão, um bouquet, verdadeiramente um bouquet. Nada menos de três cravos vermelhos e duas rosas tela de ouro.

Sinhá Flor está ali, a dois passos, bebericando um vermute, em companhia dumas raparigas.

Lopes entra, pára, relança o olhar pela sala, corresponde à saudação de alguns camaradas com um gesto intraduzível pelo que tinha de largo e de ridículo, arranca da lapela o seu buquê e desfolha-o, desfolha-o na cabeça da Mameluca!

O escândalo foi indizível!

Ato contínuo, como se houvera feito a cousa mais simples deste mundo, e enquanto as senhoras assim afrontadas se retiravam, dirige-se ao balcão, pede um copo de vinho do Porto e numa voz estridente, volta-se para os assistentes: Viva la gracia! ${ }^{17}$

Gonzaga Duque, autor do romance Mocidade morta, tem um livro de contos, Horto de Mágoas, um dos primeiro livros sobre arte no país, A arte brasileira, e um livro de história, Revoluções brasileiras. E ainda interfere no cenário cultural da época com seus inúmeros artigos, escritos entre 1882 e 1911, reunidos em Graves e frívolos, Contemporâneos e Impressões de um amador. Em seu romance - uma das poucas narrativas sobre as artes plásticas na literatura brasileira -, o personagem principal é um crítico, que, na convivência com vários artistas jovens e boêmios, tenta formar um grupo que possa imprimir uma direção impressionista, moderna, à arte que se fazia no país. O romance tem chaves, os personagens podem ser vistos como os pintores seus contemporâneos e ele mesmo. Pode ser visto como um romance ensaístico, na medida em que discute a arte do país e da Europa, em longas passagens, consideradas pela crítica da época como digressões mal resolvidas. Mocidade morta é uma narrativa demolidora, irreverente, sua visão da cultura brasileira quer virar pelo avesso concepções vigentes e aceitas pela maioria. As palavras do crítico Camilo Prado ao jovem pintor, um dos principais personagens do romance, dão uma interpretação do país:

17. Ver o diário do autor publicado em LINS (1991). 
Somos assim, meu caro sr. Agrário, somos assim. Não temos perseverança nem idéias; quando muito pedimos emprestado à França, a Portugal mesmo, suas idéias que não compreendemos, mas que nos trazem o deslumbramento das novidades, e começamos a dançar em derredor delas como selvagens em torno de um manipanso. Somos assim, meu amigo, e por isso seremos eternamente uns imitadores, minados pela ociosidade, aterrorizados pela obstinação das criações, preteridos pela imbecilidade ovante... ${ }^{18}$

José Veríssimo, no entanto, comentou que o romance deveria ser totalmente reescrito, parecia a ele ininteligível.

Alguns artigos de Gonzaga Duque, quase crônicas, tornam-se lugares de memória, contando histórias de ruas, cafés e cabarés que já tinham desaparecido no momento em que escreve. É a articulação de uma história contada a partir da experiência, numa linguagem que, nos contos, toma o máximo de densidade, aproximando-os do poema em prosa. Essas pequenas narrativas tematizam questões estéticas como os limites da representação e o sublime. A música está presente nesses textos com repetições e cortes, criando ritmos e silêncios que desenvolvem as relações entre música, palavra e imagem. A relação da música com a experiência poética é uma relação interna, da própria composição e da produção do sentido. O que é essencial na experiência poética do simbolismo. A música representa o que não pode ser representado, a base supersensível da subjetividade.

O que interessava aos simbolistas, como viu Valéry, não era agradar a um público pouco exigente, mas criar leitores, criar um público para o que escreviam. Não tinham medo de inventar, de correr riscos, na aventura absoluta, ética e estética que para eles era a literatura. Daí pode-se entender também sua criação incessante de pequenas revistas, dissidentes da grande imprensa, como a Revista Contemporânea, de Luiz Edmundo, a Rosa-Cruz, de Saturnino de Meirelles, e várias outras revistas simbolistas, que pululavam nessa virada do século, com a intenção de formar esse público raro.

A força poética da crítica de Gonzaga Duque, que escapa ao rigor do método e ao fechamento do conceito, provoca o pensamento. Ela permitiria também, articulando a memória, rearticular a história ou mesmo criar uma história como faz Gonzaga Duque em A arte brasileira e Revoluções brasileiras, em que

18. GONZAGA DUQUE, 1995 , p. 78. 
cria imagens para um passado até então não contado, o Quilombo dos Palmares, a Cabanada, a Balaiada e outras revoltas. Trabalha contra o esquecimento, criando hieróglifos utópicos, imagens críticas que apontam ao ainda não realizado. Como exemplo, as passagens sobre Zumbi, Frei Caneca e Anita Garibaldi.

A arte brasileira, primeiro livro seu, escrito aos 25 anos, em 1888, é um longo ensaio, dividido em partes, que tenta fazer uma história do que ainda não existia como sistema no Brasil. Não tínhamos um museu de artes plásticas; no Rio, apenas quatro lojas expunham quadros, além da Escola de Belas-Artes com um salão nacional. Com ironia, o livro faz uma reflexão sobre a cultura brasileira e sua arte, que julga menosprezada como ocupação de negros e mulatos, de pobres que não tinham acesso às profissões letradas. Diz que a Missão Francesa interrompeu uma arte que vinha se fazendo; já tínhamos por volta de 1800 uma tradição visual. No início do livro, faz a caricatura do colonizador português, ao descrever o desembarque de D. João VI no cais da cidade:

Era solene o espetáculo. O príncipe, gordo e risonho, pôs o pé augusto em terra sua, ao lado de d. Carlota Joaquina, cercado por seus reverentes vassalos e bem-amados frades, enquanto d. Maria I dava gargalhadas estridentes e fazia esgares para os que estavam a seu lado, aparentemente humildes e resignados.

A ironia não o exime de apontar na terceira parte, no quadro do pintor Victor Meirelles, "A primeira missa", a falta de invenção. O quadro histórico tem como referência imediata a "Misse em Kabilie", pintada pelo neoclássico, Horace Vernet, e segue os rígidos preceitos acadêmicos: "tendo aprendido a idolatrar a forma, a pureza da linha, nunca tentou abandonar este culto, porque para tanto fora preciso partir o coração" Partir o coração significa explorar limites, problematizar a representação, se arrojar na aventura absoluta que é a arte para o simbolismo. O livro termina com uma reflexão sobre o que se produzia no país:

Daí, portanto, os insignificantes conhecimentos dos nossos antigos artistas e a superficialidade dos modernos. Para chegar-se a esta conclusão basta lançar rápido olhar para as mais recentes produções. Todas as obras acusam um grande torpor intelectual, nenhum pensamento superior as

19. GONZAGA DUQUe, 1995 , p. 173. 
veste, algumas são concluídas com enorme predileção pelo acabamento e não raras com certa habilidade, mas, em essência, se nos apresentam de uma pobreza profunda. [...] Em um país colocado nas atuais circunstâncias em que se acha o Brasil, só estudos longos e muita meditação podem elevar o artista à sua merecida posição e dar-lhe os elementos para sua independência de pensar e agir. ${ }^{20}$

No seu livro, Contemporâneos, há um artigo, "O Salão de 1905", um texto de crítica singular na sua composição. O crítico entra nos salões à procura de uma coisa rara: imaginação. Cria uma imagem para falar das imagens que vê e parece reatualizar o poema de Baudelaire, "A uma passante". O crítico, que tem como obrigação escrever sobre o salão, ao entrar, depara com uma mulher desconhecida e misteriosa que o encanta e o instiga, o aturde é sua palavra. Buscando essa figura que desaparece e reaparece entre os quadros vai descrevendo o que vê, até que ela se vai. Isso que não encontra é personificado na desconhecida que passa e que ele vislumbra, mas não chega a conhecer. Há um ritmo no texto que alterna frases curtas, que dão a rapidez do olhar de relance, com outras longas, minuciosas na descrição. Incorpora um diálogo com um espectador que não entende nada do que vê e ironiza certas paisagens: as "marinhazinhas com barquinhos". Quando revê a mulher, depois de falar de alguns quadros fica "desatinado, sem pensar, sem saber o que fazer", passa para as esculturas e ataca a política das encomendas. Lembra Schubert e destaca as telas de Visconti e Roberto Mendes. O que se passa entre ele e a desconhecida alegoriza a relação do crítico com a arte - a surpresa e o aturdimento que a desconhecida lhe causa, o aproximar-se e o afastar-se e depois a fuga, a impossibilidade de alcançá-la. A crítica não desfaz o enigma da arte, o objeto lhe escapa. Para Agamben, numa reflexão recente, o crítico deve criar as condições de inacessibilidade do objeto. ${ }^{21}$

Nestor Victor, outro crítico simbolista, é também contista. Além dos textos de crítica, reunidos em Obra crítica, publica dois livros de contos, Signos e Amigos, e um ensaio longo, Paris, ${ }^{22}$ interessante para se pensar sobre o ensaio. Tendo vivido quatro anos na capital francesa, tenta compreender a cidade, comparando-a com o Rio, ou, compreender o Rio nessa comparação com Paris.

20. GONZAGA DUQUe, 1995, p. 261.

21. AGAMBEN, 1998.

22. VICTOR, 1911. 
Vai mostrando lá e cá, acertos, problemas e diferenças. Nesse livro singular, Nestor Victor trabalha o ensaio em tensão com outro gênero que é a narrativa de viagens. Foi de seus trabalhos o que mais repercutiu. O escritor morou, de 1902 a 1905, na cidade de Paris como correspondente de O Paiz e do Correio Paulistano. Mas o livro é escrito em 1911, com o subtítulo de "impressões de um brasileiro". E nele um pensamento sobre o Brasil vai-se articulando com suas lembranças da viagem.

Logo nos três primeiros capítulos, já pelos títulos se revela um leitor de Baudelaire e Poe: "A rua", "Quem passa", "A alma da multidão". Começa com as imagens da multidão nas duas cidades e vem desenhando as diferenças, à medida que vão aparecendo. Seu método é mostrar por contraste, o que vai-se configurando no decorrer do texto. Assume o ensaio como um auto-retrato, isto é, faz de si o palco da experiência intelectual. Diz: "É preciso haver-se estado na Europa para vermos que lados imprevistos do nosso ser ali se revelam, generalidades e defeitos que quase nem nos apercebemos, vivendo no nosso próprio meio”. 23

Em capítulos que valem como fragmentos, suficientes em si mesmos, não tem a pretensão de esgotar o assunto, mas criar imagens dos dois lados. Começa com a rua e fala da diferença de luz, nossos horizontes luminosos contrastam com a sombra européia. A Av. Central lhe parece uma enorme caixa de brinquedos em que há de tudo. Diz que somos de uma ensandecida imaginação, sem medida e sem freio: "Só o novo admiramos. Lá o arquiteto teve de aceitar o que já havia, sabendo tirar disso o melhor partido possível. Aqui, com exceção desta ou daquela rua, fez-se tábua rasa, como se tivesse passado um terremoto na edificação e construiu-se tudo de novo." ${ }^{24}$

Como um viajante moderno, em Paris, lê os nomes dos boulevards, squares e carrefours, as tabuletas e anúncios e reflete:

As placas de nomes próprios, as tabuletas comerciais no alto das portas, os títulos nos edifícios públicos, tudo quanto é de caráter genuinamente francês, é feito com gosto, é discreto sem exagero de bárbaros nem tampouco com intenções americanistas de descarado reclamo - mas é tudo uniforme, reprodução da reprodução pela milésima vez, porque obedece a um tipo que se impôs como o tipo aceitável exclusivo. ${ }^{25}$

23. VICTOR, 1911, p. V.

24. VICTOR, 1911, p. 34

25. VICTOR, 1911, p. 38 
Chama Paris de Cidade Única, que ao ler vai criando. Escreve a partir da memória e de uma experiência pessoal, do vivido. Seu percurso é marcado pela sedução, pelo fascínio que essa cidade lhe desperta. É pela mulher que ele vai estabelecendo as diferenças. A mulher francesa é um modelo. Aqui, no que ele chama de nossas vastas aldeias, "as mulheres são prisioneiras em gaiolas de outro, dão-lhes todas as comodidades, menos a liberdade de locomoção. Uma européia se distingue pelo seu andar decidido e firme. Aqui entre nós não é de bom tom que a mulher caminhe com igual desembaraço e firmeza." ${ }^{26}$ Diz que lá a mulher pára para ver o que acontece na rua, enquanto as damas daqui fugiriam espavoridas, porque entre nós "mulher não se mete em questão".

Fala de uma cordialidade na nossa expressão, antes de Ribeiro Couto e Sérgio Buarque de Holanda:

Nós somos mais simples nas nossas cerimônias, mas damos ao nosso trato expressão mais cordial. Nós falamos sorrindo e temos mel nas palavras, meiguice nos olhos quando queremos ser amáveis. Eles acreditam que nos conquistam dando exemplo de respeito humano. ${ }^{27}$

Em outro capítulo, "A alma da multidão", fala dos restaurantes, dos cafés:

Os cafés aqui vão sendo subtituídos por casas à feição americana, vertiginosa e prática, antes tinham jornais. Nos cafés fez-se a abolição, neles fez-se a república tramou-se contra Floriano e contra Prudente por fim. Data de Campos Sales, i.e., do arrocho financeiro, a modificação desses nossos hábitos. Nos cafés da Europa o que mais se bebe é álcool, bebem e lêm jornais e jogam. Escrevem-se cartas com papel, envelope, pena e tinta que a casa fornece. ${ }^{28}$

Em outro capítulo, que tem como título "A questão social”, aponta o trágico da civilização francesa. Diz que o suicídio cresce e traz dados comprovadores, deixa ver os abismos dessa sociedade e acrescenta que o espetáculo é inquietante. Fala ainda das colônias e da miséria.

26. VICTOR, 1911, p. 203.

27. VICTOR, 1911, p. 42-43.

28. VICTOR, 1911, p. 114 
São ao todo quatorze capítulos, fragmentos que não pretendem tratar de tudo. No capítulo, "Liberdade igualdade e fraternidade", ironiza a sociedade, que divide-se ali entre condecorados e não condecorados: "uma fita na lapela em França produz à rua os efeitos práticos que se conseguem com um anel de doutor entre nós; toda a gente já nos trata de outro modo". ${ }^{29}$ Mas conclui que para uma coisa há em Paris liberdade: para o amor.

Ligados ao movimento simbolista da virada do século, os dois escritores apresentam um pensamento crítico que problematiza a arte e a cultura brasileira. O ensaio é um gênero que se caracteriza por poder falar do que se furta a qualquer solução. Há uma negatividade moderna nessa crítica, exercida no ensaio, que desfaz idéias prontas e procura produzir uma nova reflexão com um direcionamento utópico ou heterotópico: criar um outro modo de pensar o país e com isso transformar na direção de algo que fica ainda não realizado, mas permanece como um princípio regulativo: um ideal de arte, um ideal de cidade.

Abstract: The article examines the simbolist writers of the turn of the $19^{\text {th }}$ century, focusing the essays of two critics: the art critic and novelist, Gonzaga Duque and the literature critic and also novelist, Nestor Victor. In both one can observe a modern and original thinking about brazilian art and culture. Keywords: Simbolism, essay, criticism.

\section{Referências Bibliográficas}

AGAmBEN, Giorgio. Stanze. Tradução de Yves Hersant. Paris: Rivages, 1998.

BERARDINELLI, Alfonso. La forma del saggio: definizione e atualitá di un genere letterário. Venezia: Marsilio, 2002.

CARPEAUX., Otto Maria. Ensaios reunidos. Rio de Janeiro: Topbooks, 1995. v. I.

GONZAGA DUQUE. A arte brasileira. Organizado por Tadeu Chiarelli. Campinas: Mercado das letras, 1995.

GONZAGA DUQUE. Mocidade morta. Rio de Janeiro: Fundação Casa de Rui Barbosa, 1995.

29. VICTOR, 1911, p. 210 
GONZAGA DUQUE. Revoluções brasileiras. Organizado por Vera Lins e Francisco Foot Hardman. São Paulo: Fapesp; Unesp, 1998

LINS, Vera. Gonzaga Duque e a estratégia do franco-atirador. Rio de Janeiro: Tempo brasileiro, 1991.

LINS, Vera. Novos Pierrôs, velhos saltimbancos. Curitiba: Secretaria de Cultura do Paraná, 1998.

LINS, Vera; CASTAÑON GUIMARÃES, Julio. Impressões de um amador. Belo Horizonte: Editora da UFMG, 2001.

LUKÁCS, Georges. L'âme et les formes. Tradução de Guy Haarscher. Paris: Gallimard, 1974.

MOREYRA, Álvaro. As amargas, não. Rio de Janeiro: Editora Lux, 1954.

OLIVEIRA, Franklin de. Literatura e civilização. Rio de Janeiro: Difel, 1978.

PAES, José Paulo. Gregos e baianos. São Paulo: Brasiliense, 1985.

RANCIÈRE, Jacques. Malaise dans l'esthétique. Paris: Galilée, 2004.

VICTOR, Nestor. Paris. Rio de Janeiro: Livraria Francisco Alves, 1911.

WILDE, Oscar. Obra completa. Rio de Janeiro: Nova Aguilar, 2003. 